NASA CONTRACTOR REPOR T

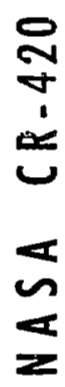

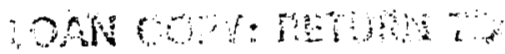

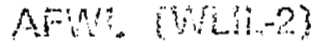

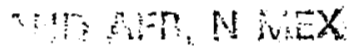

\title{
THE ECKERT REFERENCE FORMULATION APPLIED TO HIGH-SPEED LAMINAR BOUNDARY LAYERS OF NITROGEN AND CARBON DIOXIDE
}

by H. A. Simon, C. S. Liu, and J. P. Hartnett

Prepared under Grant No. NSG-356 by

UNIVERSITY OF DELAWARE

Newark, Del.

for

NATIONAL AERONAUTICS AND SPACE ADMINISTRATION - WASHINGTON, D. C. - APRIL 1966 
THE ECKERT REFERENCE FORMULATION APPLIED TO

HIGH-SPEED LAMINAR BOUNDARY LAYERS

OF NITROGEN AND CARBON DIOXIDE

By H. A. Simon, C. S. Liu, and J. P. Hartnett

Distribution of this report is provided in the interest of information exchange. Responsibility for the contents resides in the author or organization that prepared it.

Prepared under Grant No. NSG 356 by UNIVERSITY OF DELAWARE

Newark, Del.

for

NATIONAL AERONAUTICS AND SPACE ADMINISTRATION

For sale by the Clearinghouse for Federal Scientific and Technical Information

Springfield, Virginia 22151 - Price $\$ 0.15$ 
The Eckert Reference Formulation Applied to

High-Speed Laminar Boundary Layers of Nitrogen

and Carbon Dioxide

Design calculations aimed at the determination of heat transfer, skin friction or recovery temperature in high-speed laminar boundary layers, can be extremely complex due to property variations. Considerable simplification is achieved if a constant property analysis can be used with the properties determined at suitably defined reference conditions.

In Ref. 1, Eckert presents the following expression for the reference temperature applicable to laminar boundary layers on surfaces at constant temperature and pressure, and for a wide range of Mach numbers:

$$
\mathrm{T}^{*}=\mathrm{T}_{\mathrm{s}}+0.50\left(\mathrm{~T}_{\mathrm{w}}-\mathrm{T}_{\mathrm{s}}\right)+0.22\left(\mathrm{~T}_{\mathrm{r}}-\mathrm{T}_{\mathrm{s}}\right)
$$

The constants in this equation were determined such that the reference temperature so defined, and used in a constant property analysis, gave good agreement with all the exact calculations available at that time. These calculations were concerned with air and were we11 approximated by the above approach regardless of the specific property variations assumed. This suggests that the relationship assumed for the reference temperature could also work for gases other than air, and the present work confirms this for $\mathrm{N}_{2}$ and $\mathrm{CO}_{2}$. 
Laminar boundary layer calculations have been carried out for $\mathrm{N}_{2}$ and $\mathrm{CO}_{2}$ streams allowing for variable properties (Ref. 2), thus providing the opportunity for checking the assumed reference expression on gases other than air. The property calculations are described in Ref. 3 .

Ref. 1 gives tables in which the constant property results are compared with the exact calculations of Young and Janssen (4). Percentage errors are also given. To simplify comparisons the same format has been followed here for $\mathrm{N}_{2}$ and $\mathrm{CO}_{2}$, using the same parameters.

The tables are arranged as follows:

Tab1e 1. Wall at recovery temperature

a. Nitrogen

b. Carbon dioxide

Table 2. Constant wall temperature

a. Nitrogen

b. Carbon dioxide

Table 1, column 3 and Table 2 , column 4 give values of the skin friction coefficient, $\left(C_{f} \sqrt{\operatorname{Re}}\right)_{S}$ as obtained from the exact solutions. The following column in each table reports values of this same parameter $\left(C_{f} \sqrt{R e}\right)_{s}$ obtained however by application of the reference temperature method (for this reason this column is labelled $\left.\left(C_{f} \sqrt{\operatorname{Re}}\right){ }_{s}\right)$. To obtain these values the following formulation has been used: 


$$
\left(C_{f} \sqrt{\operatorname{Re}}\right)_{S}^{*}=\left(C_{f} \sqrt{\operatorname{Re}}\right)^{*} \sqrt{\frac{\rho^{*} \mu^{*}}{\rho_{S} \mu_{S}}}=0.664 \sqrt{\frac{\rho^{*} \mu^{*}}{\rho_{S} \mu_{S}}}
$$

Here we have used one of the basic reference temperature relationships, which is derived from a constant property analysis:

$$
\left(C_{f} \sqrt{\operatorname{Re}}\right)^{*}=0.664
$$

The difference between the two tabulated values of $\left(C_{f} \sqrt{\operatorname{Re}}\right)_{S}$ though in a few instances larger than in Ref. 1, is still relatively small, being less than 2 or 3 per cent for both cases.

The recovery temperature is calculated from

$\mathrm{T}_{\mathrm{r}}^{*}=\mathrm{T}_{\mathrm{s}}+\sqrt{\mathrm{P}_{\mathrm{r}}^{*}} \frac{\mathrm{u}_{\mathrm{s}}^{2}}{2 \mathrm{C}_{\mathrm{p}}^{*}}$

where the Prandtl number and the specific heat are evaluated at the reference temperature defined by equation (1), it is compared in columns 6 and 7 of Table 1 with the value of the recovery temperature $\mathrm{T}_{\mathrm{r}}$ found from the boundary layer analysis. The percentage errors are no larger than those in Ref. 1 .

In applying the reference temperature method to the calculation of the heat transfer coefficient the analogy expression relating heat transfer and skin friction is utilized:

$\left(\frac{\mathrm{C}_{\mathrm{f}}}{2 \mathrm{St}}\right)=\left(\mathrm{P}_{\mathrm{r}}^{*}\right)^{2 / 3}$

To compare the boundary layer results with the reference temperature formula of eq. (4) the value of $\left(\mathrm{C}_{\mathrm{f}} / 2 \mathrm{St}\right)^{*}$ is determined from the exact calculations as follows: 


$$
\left(\frac{\mathrm{C}_{f}}{2 \mathrm{St}}\right) *=\left(\frac{\mathrm{C}_{f}}{2 \mathrm{St}}\right)_{\mathrm{s}} \quad \frac{\mathrm{C}^{*}}{\mathrm{C}_{\mathrm{p}_{\mathrm{s}}}}
$$

The values obtained from equations (5) and (4) are tabulated in columns (8) and (9) respectively of Table 2. The percentage error is less than 10 percent in al1 cases except one, with the deviations in general being higher for $\mathrm{CO}_{2}$ than for $\mathrm{N}_{2}$. This agreement is as good as that reported in Reference 1 , and in the case of Nitrogen it is somewhat better.

The alternative procedure proposed by Eckert is to define the heat transfer coefficient in terms of enthalpy difference:

$$
\mathrm{q}_{\mathrm{w}}=\mathrm{h}_{\mathrm{i}} \quad\left(i_{\mathrm{r}}-\mathrm{i}_{\mathrm{w}}\right)
$$

where now the enthalpy recovery factor $r_{i}$ is given by

$$
r_{i}=\frac{i^{-i} s}{u_{s}^{2} / 2}
$$

The value of the enthalpy recovery factor $r_{i}$ as taken from the boundary layer solutions is reported in column 9 of Table 2 and compared with the approximate value given as $\sqrt{\mathrm{P}_{\mathrm{r}}^{\mathrm{r}}}$ in column 10. The resulting error in the use of the reference method is comparable to that in Reference 1, being of the order of 1 to 2 percent.

The heat transfer coefficient $h_{i}$ is reported in dimensionless form as $\left(\mathrm{C}_{f} / 2 \mathrm{St}_{i}\right)$ and the boundary layer calculations are shown in column 10 of Table 2. The reference method 
proposed a value of $(P *)^{2 / 3}$ for this ratio. The agreement of the approximate and exact values is even better than that reported in Reference 1 .

\section{Conclusions and Recommendation}

The use of the reference temperature method yields approximations for $\mathrm{N}_{2}$ and $\mathrm{CO}_{2}$ laminar boundary layers which are as good as those of Ref. 1 for air. If the specific heat varies over a wide range or if dissociation occurs it is recommended as in Reference 1 , though this remains to be verified, that properties be evaluated at a reference enthalpy rather than the reference temperature, where the reference enthalpy is given by:

$$
i *=i_{s}+0.5\left(i_{w}-i_{s}\right)+0.22\left(i_{r}-i_{s}\right)
$$


Nomenclature

$\mathrm{C}_{\mathrm{f}}=\frac{\tau_{\mathrm{W}}}{\frac{\mathrm{I}}{2} \rho \mathrm{u}_{\mathrm{S}}^{2}}=$ local skin friction coefficient

$C_{p}=$ Specific heat at constant pressure

$h=q_{W} /\left(T_{r}-T_{W}\right)=1$ local heat transfer coefficient

$h_{i}=q_{w} /\left(i_{r}-i_{w}\right)=10 c a l$ enthalpy difference heat transfer coefficient

$i=$ enthalpy

$\operatorname{Pr}=\operatorname{Prandt} 1$ number

$\mathrm{q}=$ heat flow per unit time and area

$r=\left(T_{I}-T_{s}\right) / \frac{u_{S}^{2}}{2 C_{p}}=$ recovery factor

$r_{i}=\left(i_{r}-i_{s}\right) / \frac{u}{2}=$ enthalpy recovery factor

$S t_{i}=h_{i} / \rho u_{s}=$ Stanton number based on enthalpy difference

$\mathrm{T}=$ temperature

$\mathrm{u}=$ velocity

$\mu=$ viscosity

$\rho=$ density

$\tau=$ shearing stress

Subscripts

$$
\begin{aligned}
& \mathbf{i}=\text { based on enthalpy } \\
& \mathrm{r}=\text { recovery } \\
& \mathrm{s}=\text { in free stream } \\
& \mathrm{w}=\text { at wall }
\end{aligned}
$$

\section{Superscripts}

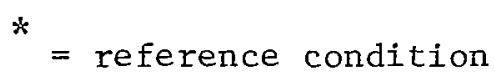


TABLE 1 a

$\mathrm{N}_{2} \quad$ Recovery Case

\begin{tabular}{|c|c|c|c|c|c|c|c|c|c|c|}
\hline $\mathrm{T}_{\mathrm{S}}^{\mathrm{O}_{\mathrm{K}}}$ & $\mathrm{M}_{\mathrm{s}}$ & $\left(\mathrm{C}_{f} \sqrt{\mathrm{Re}}\right)_{\mathrm{s}}$ & $\left(C_{f} \sqrt{R e}\right) * \frac{*}{s}$ & $\begin{array}{l}\text { per } \\
\text { cent }\end{array}$ & $\stackrel{\mathrm{T}}{\mathrm{T}}_{\mathrm{K}}$ & $\begin{array}{l}\mathrm{T}_{\tilde{r}}^{*} \\
\mathrm{o}_{\mathrm{K}}\end{array}$ & $\begin{array}{l}\text { per } \\
\text { cent }\end{array}$ & $r_{i}$ & $\sqrt{P_{r}^{F}}$ & $\begin{array}{l}\text { per } \\
\text { cent }\end{array}$ \\
\hline 218 & 4 & 0.574 & 0.569 & -0.9 & 791 & 790 & -0.1 & 0.836 & 0.846 & 1.2 \\
\hline 555 & 4 & 0.564 & 0.560 & -0.7 & 1843 & 1812 & -1.7 & 0.839 & 0.852 & 1.5 \\
\hline 1110 & 4 & 0.574 & 0.568 & -1.0 & 3409 & 3382 & -0.8 & 0.841 & 0.851 & 1.2 \\
\hline 218 & 8 . & 0.485 & 0.481 & -0.8 & 2274 & 2199 & -3.3 & 0.835 & 0.853 & 2.2 \\
\hline 218 & 12 & 0.432 & 0.426 & -1.4 & 4570 & 4438 & -2.9 & 0.835 & 0.852 & 2.0 \\
\hline \multicolumn{3}{|c|}{ TABLE $1 \mathrm{~b}$} & & & $\mathrm{CO}_{2}$ & Recovery & Case & & & \\
\hline 218 & 4 & 0.640 & 0.640 & 0 & 634 & 610 & -3.8 & 0.854 & 0.860 & 0.7 \\
\hline 555 & 4 & 0.612 & 0.610 & -0.3 & 1271 & 1248 & -1.8 & 0.834 & 0.842 & 1.0 \\
\hline 1110 & 4 & 0.607 & 0.604 & -0.5 & 2329 & 2317 & -0.5 & 0.827 & 0.836 & 1.1 \\
\hline 218 & 8 & 0.575 & 0.578 & 0.5 & 1554 & 1452 & -6.6 & 0.832 & 0.841 & 1.1 \\
\hline 555 & 8 & 0.536 & 0.534 & -0.4 & 3103 & 3020 & -2.7 & 0.821 & 0.834 & 1.6 \\
\hline 218 & 12 & 0.521 & 0.522 & 0.2 & 2917 & 2752 & -5.7 & 0.821 & 0.836 & 1.8 \\
\hline
\end{tabular}


$\mathrm{N}_{2} \quad$ Constant Wa11 Temperature

\begin{tabular}{|c|c|c|c|c|c|c|c|c|c|c|}
\hline $\mathrm{T}_{\mathrm{s}}{ }^{\mathrm{O}} \mathrm{K}$ & ${ }_{\mathrm{W}}^{\mathrm{T}}{ }_{\mathrm{K}}^{\mathrm{O}_{\mathrm{N}}}$ & $\mathrm{M}_{\mathrm{s}}$ & $\left(C_{f} \sqrt{R e}\right)_{s}$ & $\left(C_{f} \sqrt{R e}\right) \frac{\xi}{S}$ & $\begin{array}{l}\text { per } \\
\text { cent }\end{array}$ & $\left(C_{f} / 2 S t\right) *$ & $(\operatorname{Pr} *)^{2 / 3}$ & $\begin{array}{l}\text { per } \\
\text { cent }\end{array}$ & $\left(C_{f} / 2 S t_{i}\right)$ & $\begin{array}{l}\text { per } \\
\text { cent }\end{array}$ \\
\hline 218 & 436 & 0 & 0.633 & 0.612 & -3.3 & 0.806 & 0.804 & -0.2 & 0.807 & 0.1 \\
\hline 218 & 1308 & 0 & 0.553 & 0.547 & -1.0 & 0.798 & 0.801 & 0.4 & 0.801 & 0.4 \\
\hline 1110 & 555 & 0 & 0.707 & 0.693 & -2.0 & 0.811 & 0.801 & -1.2 & 0.810 & -0.1 \\
\hline 218 & 436 & 4 & 0.607 & 0.597 & -1.6 & 0.778 & 0.800 & 2.8 & 0.800 & 2.8 \\
\hline 218 & 1308 & 4 & 0.540 & 0.529 & -2.0 & 0.776 & 0.799 & 3.0 & 0.799 & 3.0 \\
\hline 555 & 555 & 4 & 0.624 & 0.615 & -1.4 & 0.768 & 0.800 & 4.2 & 0.806 & 4.9 \\
\hline 555 & 1110 & 4 & 0.592 & 0.582 & -1.7 & 0.776 & 0.802 & 3.4 & 0.807 & 4.0 \\
\hline 555 & 1665 & 4 & 0.571 & 0.559 & -2.1 & 0.782 & 0.806 & 3.1 & 0.805 & 2.9 \\
\hline 1110 & 555 & 4 & 0.651 & 0.638 & -2.0 & 0.791 & 0.806 & 1.9 & 0.809 & 2.3 \\
\hline 218 & 436 & 8 & 0.555 & 0.542 & -2.3 & 0.749 & 0.801 & 6.9 & 0.802 & 7.1 \\
\hline 218 & 1308 & 8 & 0.513 & 0.503 & -1.9 & 0.764 & 0.803 & 5.1 & 0.802 & 5.0 \\
\hline 218 & 436 & 12 & 0.509 & 0.493 & -3.1 & 0.771 & 0.805 & 4.4 & 0.803 & 4.2 \\
\hline 218 & 1308 & 12 & 0.485 & 0.473 & -2.5 & 0.776 & 0.806 & 3.9 & 0.803 & 3.5 \\
\hline
\end{tabular}


TABLE $2 \mathrm{~b}$

$\mathrm{CO}_{2}$ Constant Wall Temperature

\begin{tabular}{|c|c|c|c|c|c|c|c|c|c|c|}
\hline $\mathrm{T}_{s} \mathrm{OK}$ & $\mathrm{T}_{\mathrm{W}}{ }^{\circ} \mathrm{K}$ & $\mathrm{M}_{\mathrm{s}}$ & $\left(C_{f} \sqrt{R e}\right)_{S}$ & $\left(C_{f} \sqrt{R e}\right) \stackrel{*}{s}$ & $\begin{array}{l}\text { per } \\
\text { cent }\end{array}$ & $\left(C_{f} / 2 S t\right) *$ & $(\operatorname{Pr} *)^{2 / 3}$ & $\begin{array}{l}\text { per } \\
\text { cent }\end{array}$ & $\left(C_{f} / 2 S t_{i}\right)$ & $\begin{array}{l}\text { per } \\
\text { cent }\end{array}$ \\
\hline 218 & 436 & 0 & 0.661 & 0.633 & -1.2 & 0.838 & 0.834 & -0.5 & 0.835 & -0.4 \\
\hline 218 & 1308 & 0 & 0.608 & 0.606 & -0.33 & 0.798 & 0.808 & 1.3 & 0.802 & 0.5 \\
\hline 1110 & 555 & 0 & 0.697 & 0.683 & -2.0 & 0.818 & 0.801 & -2.1 & 0.813 & -0.6 \\
\hline 218 & 436 & 4 & 0.652 & 0.636 & -2.5 & 0.759 & 0.825 & 8.7 & 0.813 & 7.1 \\
\hline 218 & 1308 & 4 & 0.600 & 0.593 & -1.2 & 0.775 & 0.800 & 3.2 & 0.794 & 2.5 \\
\hline 555 & 555 & 4 & 0.648 & 0.635 & -2.0 & 0.762 & 0.805 & 5.6 & 0.802 & 5.2 \\
\hline 555 & 1110 & 4 & 0.619 & 0.607 & -1.9 & 0.757 & 0.797 & 5.3 & 0.786 & 3.8 \\
\hline 555 & 1665 & 4 & 0.595 & 0.592 & -0.5 & 0.773 & 0.792 & 2.5 & 0.791 & 2.3 \\
\hline 1110 & 555 & 4 & 0.669 & 0.658 & -1.6 & 0.783 & 0.793 & 1.3 & 0.799 & 2.0 \\
\hline 218 & 436 & 8 & 0.627 & 0.627 & 0 & 0.726 & 0.809 & 11.4 & 0.797 & 9.8 \\
\hline 218 & 1308 & 8 & 0.585 & 0.575 & -1.7 & 0.736 & 0.796 & 8.2 & 0.778 & 5.7 \\
\hline 555 & 555 & 8 & 0.608 & 0.601 & -1.2 & 0.757 & 0.793 & 4.8 & 0.789 & 4.2 \\
\hline 555 & 1110 & 8 & 0.589 & 0.581 & -1.4 & 0.752 & 0.790 & 5.1 & 0.782 & 4.0 \\
\hline 555 & 1665 & 8 & 0.571 & 0.563 & -1.4 & 0.754 & 0.789 & 4.6 & 0.778 & 3.2 \\
\hline 218 & 436 & 12 & 0.595 & 0.588 & -1.2 & 0.742 & 0.797 & 7.4 & 0.790 & 6.5 \\
\hline 218 & 1308 & 12 & 0.564 & 0.560 & -0.7 & 0.743 & 0.791 & 6.5 & 0.779 & 4.8 \\
\hline
\end{tabular}




\section{References}

1. "Engineering Relations for Heat Transfer and Friction in High-Velocity Laminar and Turbulent Boundary-Layer Flow over Surfaces with Constant Pressure and Temperature,"

E. R. G. Eckert, Trans. A.S.M.E., Vo1. 78,August, 1956, p. 1273 .

2. "Mass Transfer Cooling In Laminar Boundary Layers with Hydrogen Injected into Nitrogen and Carbon Dioxide Streams," C. S. Liu, M.M.E. Thesis, University of Delaware, June, 1965.

3. "Properties of Hydrogen:Nitrogen and Hydrogen:Carbon Dioxide Mixtures," H.A. Simon, C.S. Liu and J. P. Hartnett, University of Delaware, Department of Mechanica1 Engineering T. N. 3, January, 1965.

4. "The Compressible Boundary Layer," G. B. W. Young and E. Janssen, Jn1. of the Aero. Sciences, Vol. 19, 1952. 
"The aeronautical and space activities of the United States shall be conducted so as to conlribute. . . to the expansion of buman knowledge of phenoment in the atmosphere and space. The Administration shall provide for the widest practicable and appropriate dissemination of information concerning its activities and the results thereof."

-National Aeronautics and Space Act of 1958

\section{NASA SCIENTIFIC AND TECHNICAL PUBLICATIONS}

TECHNICAL REPORTS: Scientific and technical information considered important, complete, and a lasting contribution to existing knowledge.

TECHNICAL NOTES: Information less broad in scope but nevertheless of importance as a contribution to existing knowledge.

TECHNICAL MEMORANDUMS: Information receiving limited distribution because of preliminary data, security classification, or other reasons.

CONTRACTOR REPORTS: Technical information generated in con. nection with a NASA contract or grant and released under NASA auspices.

TECHNICAL TRANSLATIONS: Information published in a foreign language considered to merit NASA distribution in English.

TECHNICAL REPRINTS: Information derived from NASA activities and initially published in the form of journal articles.

SPECIAL PUBLICATIONS: Information derived from or of value to NASA activities but not necessarily reporting the results of individual NASA-programmed scientific efforts. Publications include conference proceedings, monographs, data compilations, handbooks, sourcebooks, and special bibliographies.

Details on the availability of these publications may be obtained from:

SCIENTIFIC AND TECHNICAL INFORMATION DIVISION

NATIONAL AERONAUTICS AND SPACE ADMINISTRATION

Washington, D.C. 20546 